\title{
Acute exacerbation of idiopathic pulmonary fibrosis: incidence, risk factors and outcome
}

\author{
J.W. Song, S-B. Hong, C-M. Lim, Y. Koh and D.S. Kim
}

ABSTRACT: Although acute exacerbation of idiopathic pulmonary fibrosis (IPF) has become well recognised, the reported incidence and outcomes are highly variable, and risk factors are unknown. The aim of this study was to estimate the incidence, risk factors and impact of acute exacerbations, and other known causes of rapid deterioration.

This was a retrospective review of 461 patients with IPF (269 cases were biopsy-proven).

The median follow-up period was $\mathbf{2 2 . 9}$ months. Rapid deterioration requiring hospitalisation occurred in 163 (35.4\%) patients, with multiple episodes in 42 patients. Acute exacerbation was the most frequent cause $(55.2 \%)$, followed by infection. The 1- and 3-yr incidences of acute exacerbation were $\mathbf{1 4 . 2}$ and $\mathbf{2 0 . 7 \%}$, respectively. Never having smoked and low forced vital capacity (FVC) were significant risk factors. The in-hospital mortality rate was $50.0 \%$, and the 1and 5-yr survival rates from the initial diagnosis were 56.2 and $\mathbf{1 8 . 4 \%}$, respectively. Acute exacerbation was a significant predictor of poor survival after the initial diagnosis, along with increased age, low FVC and diffusing capacity of the lung for carbon monoxide, and steroid use with or without cytotoxic therapy.

1- and 3-yr incidences of acute exacerbation were 14.2 and $20.7 \%$, respectively. Never having smoked and low FVC were risk factors. Acute exacerbation had a serious impact on the overall survival of the patients with IPF.

KEYWORDS: Acute exacerbation, idiopathic pulmonary fibrosis, incidence, prognostic factors, risk factors, survival

$\mathbf{T}$ he natural course of idiopathic pulmonary fibrosis (IPF) is not clearly defined, and the clinical course among individual patients is highly variable [1]. Although it has become more evident that acute exacerbation (AE) of IPF, the sudden acceleration of disease process or acute injury superimposed on an already diseased lung, can occur, the incidence, risk factors and outcomes of AE remain unknown. The results of previous reports are variable, probably due to the small numbers of subjects and different definitions for AE. Therefore, COLLARD et al. [2] recently proposed diagnostic criteria for AE for future studies. Furthermore, clinically similar rapid deterioration (RD) can be caused by other conditions, such as infection, pulmonary embolism, pneumothorax or heart failure [3]. However, there are no reports about the incidence or outcomes of these events, except as autopsy findings or causes of death. Therefore, the aim of this study was to investigate the incidence, risk factors and outcome not only of AE using the criteria of COLLARD et al. [2], but also of RD from other causes.

\section{MATERIALS AND METHODS}

\section{Study population}

The subjects consisted of 461 patients (269 confirmed by surgical lung biopsy) diagnosed as having IPF according to the American Thoracic Society (ATS)/European Respiratory Society (ERS) consensus classification [4] at the Asan Medical Center, Seoul, South Korea from 1990 to 2009. Most of the biopsied patients were included in our previous reports [5-7].

\section{Methods}

RD was defined as an acute (within 30 days) worsening of dyspnoea requiring hospitalisation and the presence of newly developed radiologic

\section{AFFILIATIONS}

Dept of Pulmonary and Critical Care Medicine, Asan Medical Center, University of Ulsan College of Medicine, Seoul, South Korea.

\section{CORRESPONDENCE}

D.S. Kim

Dept of Pulmonary and Critical Care Medicine, Asan Medical Center University of Ulsan College of Medicine

388-1

Pungnap-2-dong

Songpa-gu

Seoul

South Korea

E-mail: dskim@amc.seoul.kr

Received:

Oct 092009

Accepted after revision:

June 122010

First published online:

July 012010 
abnormalities. AE was defined by the criteria of COLLARD et al. [2] (supplementary Table E1). Briefly, AE refers to a sudden aggravation of dyspnoea within 30 days with new bilateral lung infiltration in patients with known IPF or high-resolution computed tomography (HRCT) evidence of IPF without evidence of pulmonary infection or other known causes. Cases in which all these criteria were fulfilled were classified as "definite $\mathrm{AE}^{\prime}$ " and subjects who had not undergone endotracheal aspiration or bronchoalveolar lavage (BAL), but fulfilled all other criteria, were classified as "suspected AE". Clinically suspected infections (symptoms such as grossly purulent sputum and rapid resolution of symptoms in response to antibiotics alone) without an identified organism were categorised as "suspected infection".

All data were obtained from medical records. Although this was a retrospective study, we had an investigation protocol for suspected AE with new bilateral lung infiltration (supplementary Table E2). All microbiological studies and BAL were attempted in all patients, and echocardiography or embolism HRCT were performed in patients with suspected heart failure (on clinical/serial chest radiographs), or pulmonary thromboembolism, respectively. Survival status was obtained from medical records, the records of the National Health Insurance of Korea, Seoul, South Korea, and/or telephone interviews. Baseline clinical parameters were obtained within 1 month of the initial diagnosis.

\section{Physiological assessments}

Spirometry, diffusing capacity of the lung for carbon monoxide $(D \mathrm{~L}, \mathrm{CO})$ and total lung capacity (TLC) were measured according to the ATS/ERS recommendation [8-10], and the results were expressed as percentages of the normal predicted values (\% pred).

\section{Statistical methods}

Data are presented as mean \pm SD for continuous variables or percentages for categorical variables. Chi-squared and Fisher's exact tests were used for categorical data, and the unpaired t-test and Mann-Whitney U-test were used for continuous data. A Cox regression analysis was used to identify significant variables capable of predicting $\mathrm{AE}$ or acting as prognostic factors. A logistic regression analysis was used to identify discriminating factors between $\mathrm{AE}$ and infection or prognostic factors of $\mathrm{AE}$ at the time of $\mathrm{RD}$. The incidence of $\mathrm{AE}$ was obtained from the Kaplan-Meier survival curve by treating AE as the death variable. Survival was also evaluated using a

\begin{tabular}{lcc} 
TABLE 1 & $\begin{array}{l}\text { Incidence of acute exacerbation (AE) and rapid } \\
\text { deterioration (RD) }\end{array}$ \\
\hline Incidence $^{\#}$ & AE $^{*}$ & RD \\
\hline $\mathbf{1 - y r}$ & $58(14.2)$ & $97(23.0)$ \\
$\mathbf{2}-\mathbf{y r}$ & $71(18.8)$ & $124(31.2)$ \\
$\mathbf{3 - y r}$ & $75(20.7)$ & $134(35.4)$ \\
\hline
\end{tabular}

Data are presented as $n(\%)$. The cumulative incidences of $A E$, excluding patients first presented at the time of $\mathrm{AE}$, are $11.6 \%(1-\mathrm{yr}), 16.3 \%(2-\mathrm{yr})$ and $18.2 \%$ (3-yr). ${ }^{\#}$ : first event; ${ }^{\circ}: 14$ patients first presented at the time of $\mathrm{AE}$.
Kaplan-Meier survival curve and the log rank test. p-values $<0.05$ were considered statistically significant. All data were analysed using SPSS version 12.0 (SPSS Inc., Chicago, IL, USA).

This study was approved by the Institutional Review Board of the Asan Medical Center.

\section{RESULTS}

\section{Incidence of $A E$}

The mean age of all subjects was $63.4 \mathrm{yrs}$, and $77.7 \%$ were male. The median follow-up period was 22.9 months (range 0.1-168.3 months). During follow-up, 163 (35.4\%) patients were admitted due to RD, and $42(25.8 \%)$ of those RD patients experienced $>1$ episode of RD (range 2-4). AE occurred in 96 $(20.8 \%)$ patients, and $17(17.7 \%)$ of those AE patients experienced multiple episodes of AE (range 2-3 episodes).

The 1- and 3-yr incidences of AE (first event, unless otherwise specified) were 14.2 and $20.7 \%$, respectively (table 1). 14 patients first presented and were diagnosed with IPF at the time of AE. After the exclusion of these cases, the 1- and 3-yr incidences of AE were 11.6 and $18.2 \%$, respectively. The 1 - and 3-yr incidences of total RD were 23.0 and $35.4 \%$, respectively.

\section{Aetiologies of RD}

Among the 163 patients with RD, 23 (14.1\%) patients had a focal lesion, such as pneumothorax or focal pneumonia. The remaining $140(85.9 \%)$ patients had bilateral infiltration (bilateral ground glass attenuation (diffuse, multifocal patchy or subpleural) with or without some area of consolidation on HRCT). AE was the most frequent cause of RD (90 patients, $55.2 \%$ of RD), followed by infection ( 51 patients, $31.3 \%$ of RD) (table 2). Among the infections, opportunistic infections comprised $57.1 \%$ of documented organisms. They usually developed in the patients treated with steroids, regardless of whether or not cytotoxic agents were used (supplementary Table E3). Heart failure occurred in five patients (3.1\% of RD), and pulmonary thromboembolism was observed in two cases $(1.2 \%$ of $\mathrm{RD})$. One patient satisfying all the criteria of AE had BAL eosinophilia (28\% of RD) and rapidly improved after steroid treatment. We searched for various causes of eosinophilic pneumonia, but could not find a source of this disease. Although a biopsy was not performed at the time of RD, this patient was thought to have acute eosinophilic pneumonia, which might be a yet-unreported cause of RD.

\section{Risk factors for $A E$}

The patients with AE had lower forced vital capacity (FVC) and TLC compared to the non-RD group, even after the exclusion of the patients who first presented at the time of RD (table 3). In the univariate Cox analysis, low FVC, DL,CO and TLC, and never having smoked were significant risk factors for AE. In the multivariate analysis, among the parameters with p-values $<0.1$ in the univariate analysis, low FVC and never having smoked were significant factors (table 4).

\section{Comparison of the clinical features of $A E$ and bilateral infection}

In the patients with $\mathrm{AE}$, the frequency of fever, C-reactive protein (CRP) levels, disease duration and the percentage of neutrophils in BAL fluid were all significantly lower compared to those with infection, whereas the duration of dyspnoea and 


\begin{tabular}{|c|c|c|}
\hline TABLE 2 & $\begin{array}{l}\text { gies of rapid } \\
\text { e) }\end{array}$ & eterioration (RD; first \\
\hline Aetiology & Cases n (\%) ${ }^{\#}$ & Documented organisms $(n)$ \\
\hline Total RD & $163(35.4)$ & \\
\hline Bilateral lesions & $140(30.4)$ & \\
\hline $\mathrm{AE}$ & $90(19.5)$ & \\
\hline Definite & $57(12.4)$ & \\
\hline Suspected & $33(7.2)$ & \\
\hline Infection & $37(8.0)$ & \\
\hline Definite & $21(4.6)$ & \\
\hline Bacterial & $9(2.0)$ & $\begin{array}{l}\text { Streptococcus pneumoniae (2) } \\
\text { MRSA (1) } \\
\text { Haemophilus influenzae (4) } \\
\text { Legionella spp. (1) } \\
\text { Klebsiella pneumoniae (1) }\end{array}$ \\
\hline Viral & $7(1.5)$ & $\begin{array}{c}\text { CMV (7; } 2 \text { mixed infections } \\
\text { with RSV or Pneumocystis jiroveci) } \\
\text { Influenza virus (1) } \\
\text { RSV (1) }\end{array}$ \\
\hline Fungal & $2(0.4)$ & $\begin{array}{l}\text { Candida spp. (1) } \\
\text { Aspergillus spp. (1) }\end{array}$ \\
\hline Parasitic & $2(0.4)$ & Pneumocystis jiroveci (2) \\
\hline Mycobacterial & $1(0.2)$ & Mycobacterium tuberculosis (1) \\
\hline Suspected $^{+}$ & $16(3.5)$ & \\
\hline Heart failure & $5(1.1)$ & \\
\hline PTE & $2(0.4)$ & \\
\hline AEP & $1(0.2)$ & \\
\hline Uncertain ${ }^{\S}$ & $5(1.1)$ & \\
\hline Focal lesion & $23(5.0)$ & \\
\hline Pneumothorax & $9(2.0)$ & \\
\hline Infection & $14(3.0)$ & $\begin{array}{l}\text { Klebsiella pneumoniae (1) } \\
\text { Klebsiella oxytoca (1) } \\
\text { Streptococcus pneumoniae (1) }\end{array}$ \\
\hline
\end{tabular}

AE: acute exacerbation; PTE: pulmonary thromboembolism; AEP: acute eosinophilic pneumonia; MRSA: methicillin-resistant Staphylococcus aureus; CMV: cytomegalovirus; RSV: respiratory syncytial virus. *: percentage of total subjects $(n=461) ; "$ : identified by culture, antigen test (for $S$. pneumoniae and Legionella), or direct fluorescence monoclonal antibody stain (for $P$. jiroveci); + : cases in which no organism was identified, but infection was clinically suspected due to symptoms such as grossly purulent sputum and rapid resolution of symptoms in response to antibiotics alone; 's: cases in which no organism was identified, but the criteria for AE were not completely satisfied due to incomplete study.

the percentage of lymphocytes in BAL fluid were higher in the $\mathrm{AE}$ group (table 5). In the multivariate logistic analysis (supplementary Table E4), the percentage of neutrophils in BAL fluid and fever were significant discriminating parameters between $\mathrm{AE}$ and infection.

\section{Precipitating factors of $\boldsymbol{A E}$}

In the majority of patients, there were no identifiable precipitating factors of AE. However, 16 patients developed $\mathrm{AE}$ after the following procedures: video-assisted thoracoscopic surgery $(n=8)$; lung resection due to lung cancer $(n=3)$; operation for herniated intervertebral discs or spinal stenosis $(n=2)$; BAL $(n=1)$; vertebroplasty $(n=1)$; and transarterial chemoembolisation due to hepatocellular carcinoma $(n=1)$.

\section{Immediate outcome and prognostic factors of $A E$}

The immediate outcome of AE was very poor (fig. 1a and supplementary Table E5); the median survival was 2.2 months from the onset, and a half of the patients died during hospitalisation. About $50 \%$ of patients were admitted to an intensive care unit, and $\sim 80 \%$ of these patients died. There was no difference in outcome between patients with $\mathrm{AE}$ and infection (fig. 1a and supplementary Table E5). The causes of in-hospital death in AE included AE itself (69.6\%), infection $(23.9 \%)$, diffuse alveolar haemorrhage $(2.2 \%)$ and others $(4.3 \%)$. The causes in patients with infection were infection $(76.2 \%)$, disease progression $(4.8 \%)$, diffuse alveolar haemorrhage $(4.8 \%)$, cardiovascular disease $(4.8 \%)$ and others $(9.5 \%)$.

Among patients with $\mathrm{AE}$, nonsurvivors had shorter durations of dyspnoea, lower arterial oxygen tension $\left(\mathrm{Pa}_{\mathrm{a}} \mathrm{O}_{2}\right) /$ inspiratory oxygen fraction $\left(\mathrm{FI}, \mathrm{O}_{2}\right)$ ratios, higher CRP levels, and higher percentages of neutrophils and lower percentages of lymphocytes in BAL fluid compared with survivors (supplementary Table E6). However, the multivariate analysis revealed that only CRP was an independent predictor of survival (OR 2.467, 95\% CI 1.030-5.911; $p=0.043$; table 6). High-dose steroids were mostly used for treatment of patients with $\mathrm{AE}$; however, treatment did not affect their outcome (table 7).

\section{Impact of AE on the overall course of IPF}

AE exerted a significant impact on the overall course of the disease. After the initial diagnosis, the median survival of patients with AE was much shorter (15.5 months) than that of patients without RD (60.6 months; $\mathrm{p}<0.001$; fig. $1 \mathrm{~b}$ and supplementary Table E7). The 5-yr rate of survival of patients with $\mathrm{AE}$ was $18.4 \%$, whereas $50.0 \%$ of patients without RD survived $(p<0.001)$. In the multivariate Cox analysis, AE was a significant predictor (hazard ratio 2.592, 95\% CI 1.888-3.560; $\mathrm{p}<0.001$ ) for poor overall survival in patients with IPF (table 8). In addition to AE, old age, low FVC and DL,CO, and, interestingly, immunosuppressive therapy with steroids alone or with cytotoxic agents were independent poor prognostic factors. Not only $\mathrm{AE}$, but also $\mathrm{RD}$ of bilateral lesions had a serious impact on the overall survival (fig. $1 \mathrm{~b}$ and supplementary Table E7). Focal RD had a far weaker impact on survival.

\section{Multiple episodes of RD}

42 patients experienced more than one episode of RD, ranging from two $(n=32)$ to four $(n=1)$ episodes (supplementary Table E8). Similar to the overall trends in the first RD episodes, $\mathrm{AE}$ was the most frequent cause of second episodes (20 out of 42 patients) (supplementary Table E9) and the majority of patients $(n=15)$ had $\mathrm{AE}$ as the cause of their first episode. Infection was the next most common cause of second episodes $(n=15)$; notably, however, in the majority of these cases $(n=7)$, the prior episode had been caused by AE.

\section{DISCUSSION}

In this study, we found that one-third (35.4\%) of patients with IPF were hospitalised due to RD, and a quarter of these patients had multiple episodes. AE was the most frequent cause of RD, and $20.8 \%$ of all subjects experienced AE during 
TABLE 3 Comparison of the baseline characteristics between patients with and without acute exacerbation (AE)

\begin{tabular}{|c|c|c|c|c|c|}
\hline Characteristics & Non-RD & $\mathrm{AE}$ & $\mathrm{p}$-value & Infection ${ }^{\#}$ & p-value \\
\hline Patients & 298 & 90 & & 37 & \\
\hline Males & $228(76.5)$ & $69(76.7)$ & NS & $30(81.1)$ & NS \\
\hline Smoking & & & 0.107 & & NS \\
\hline Never smoked & $76(25.5)$ & $31(34.4)$ & & $10(27.0)$ & \\
\hline \multicolumn{6}{|l|}{ PFT \% pred $^{+}$} \\
\hline FVC & $77.6 \pm 17.0$ & $72.0 \pm 15.7$ & 0.005 & $75.5 \pm 18.5$ & NS \\
\hline$D L, C O$ & $66.4 \pm 19.0$ & $62.2 \pm 19.3$ & NS & $61.2 \pm 18.0$ & 0.088 \\
\hline TLC & $78.7 \pm 14.4$ & $73.8 \pm 15.0$ & 0.021 & $75.9 \pm 18.5$ & NS \\
\hline FEV 1 & $88.5 \pm 18.0$ & $86.0 \pm 18.3$ & NS & $89.0 \pm 17.5$ & NS \\
\hline Eosinophils & $3.2 \pm 4.6$ & $3.2 \pm 4.4$ & NS & $1.9 \pm 2.3$ & NS \\
\hline CRP $m g \cdot d^{-1+}$ & $0.5 \pm 0.7$ & $0.4 \pm 0.3$ & NS & $0.7 \pm 0.7$ & 0.055 \\
\hline Steroid with/without cytotoxic agent ${ }^{5}$ & $184(61.7)$ & $56(62.2)$ & NS & $20(54.1)$ & NS \\
\hline
\end{tabular}

Data are presented as $n$, mean \pm SD or $n(\%)$, unless otherwise stated. RD: rapid deterioration; PFT: pulmonary function test; \% pred: \% predicted; FVC: forced vital capacity; DL,CO: diffusing capacity of the lung for carbon monoxide; TLC: total lung capacity; FEV1: forced expiratory volume in 1 s; BAL: bronchoalveolar lavage; CRP C-reactive protein; NS: nonsignificant. ${ }^{*}$ : infection with bilateral lesions; ": No-RD versus infection; ${ }^{+}$: data from the patients who first presented with RD were excluded; s: within 30 days prior to RD.

follow-up. The 1- and 3-yr incidences of $\mathrm{AE}$ were 14.2 and $20.7 \%$, respectively. Never having smoked and low FVC were significant risk factors for AE. About a half of the patients died in hospital, and 1- and 5-yr survival rates from the initial diagnosis were 56.2 and $18.4 \%$, respectively. AE, older age, low FVC and DL,CO, and immunosuppressive therapy were significant predictors for poor overall prognosis.

Although there are many reports on the cause of death or occurrence of AE in patients with IPF in general $[3,7,11,12]$ and among patients with IPF admitted to an ICU [13-16], few studies have examined the incidence of RD and its impact on the course of IPF. PANOS et al. [3] reported that disease progression was the major cause of death in IPF (39\%), followed by cardiovascular disease $(27 \%)$, lung cancer $(10 \%)$, pulmonary embolism $(3 \%)$, pulmonary infection $(3 \%)$ and others $(18 \%)$. However, reports from Asia showed different trends. Our previous study revealed that IPF progression was the main cause of death $(51.4 \%$, including $\mathrm{AE}$ in $18.4 \%)$, followed by pneumonia $(9.7 \%)$, lung cancer $(4.9 \%)$, cardiovascular disease (1\%) and others (33\%) [7]. JEON et al. [11] reported IPF progression in $68 \%$ (AE in $46 \%$ ), followed by infection $(14 \%)$, lung cancer $(8 \%)$, pulmonary embolism $(2 \%)$, cardiovascular disease (2\%) and others (6\%). NAGAI et al. [12] also showed similar results: progression of IPF $(72 \%)$, lung cancer $(13 \%)$ and pulmonary infection $(8 \%)$. The low proportion of cardiovascular disease and pulmonary embolism as a cause of death in Asian IPF patients may reflect ethnic differences, namely, the low prevalence of cardiovascular disease and thromboembolism in the general population of Asia [17-20].
Several retrospective studies on IPF patients admitted to ICUs showed that the majority had no identifiable cause of RD (probably AE), whereas a smaller number of cases were caused by pneumonia, pneumothorax, heart failure or complications of operation [13-16]. KUBO et al. [21], in a prospective study of anticoagulation therapy, showed that the major causes of RD were $\operatorname{AE}(n=32$ events), pneumonia $(n=8)$, heart failure $(n=2)$ and sepsis $(n=2)$. Our present study, which comprises a much larger number of patients and includes all categories of RD (not just patients admitted to an ICU or patients who died), confirmed that $\mathrm{AE}$ was the most common cause of RD, followed by infection.

The incidence of RD in IPF has not been previously reported, and the reported incidences of AE have varied widely (5\% in 9 months and $57 \%$ in $3 \mathrm{yrs})[6,21]$, probably due to differences in AE definitions and study designs. Therefore, COLLARD et al. [2] proposed diagnostic criteria for $\mathrm{AE}$, in the hope of standardising future studies. The present report is one of the first to use the criteria of COLLARD et al. [2].

Furthermore, we found that a quarter of our enrolled RD patients had multiple episodes, which was suggested in previous reports $[6,21]$. Consecutive episodes of $\mathrm{AE}$ or $\mathrm{AE}$ followed by infection were most frequent (supplementary Table E8).

There are no previous reports regarding risk factors for the development of AE or RD. In this study, we found that patients with AE had never smoked and had significantly lower lung function compared to non-RD patients (table 3), which may 


\begin{tabular}{|c|c|c|c|}
\hline \multirow{2}{*}{$\begin{array}{l}\text { TABLE } 4 \\
\text { Parameters }\end{array}$} & \multicolumn{3}{|c|}{$\begin{array}{l}\text { Risk factors for acute exacerbation compared to } \\
\text { no episodes of rapid deterioration (RD) at the } \\
\text { time of initial diagnosis }\end{array}$} \\
\hline & & HR $(95 \% \mathrm{Cl})$ & $\mathrm{p}$-value \\
\hline \multicolumn{4}{|c|}{ Univariate Cox analysis } \\
\hline Age & & $1.021(0.997-1.047)$ & 0.093 \\
\hline Male sex & & $0.921(0.563-1.506)$ & NS \\
\hline Smoking & & $0.629(0.407-0.972)$ & 0.037 \\
\hline \multicolumn{4}{|l|}{ PFT $\%$ pred } \\
\hline FVC & & $0.975(0.960-0.989)$ & 0.001 \\
\hline$D L, C O$ & & $0.981(0.967-0.994)$ & 0.005 \\
\hline TLC & & $0.970(0.953-0.987)$ & 0.001 \\
\hline \multicolumn{4}{|l|}{$\mathrm{BAL}$} \\
\hline Macroph & & $0.991(0.975-1.008)$ & NS \\
\hline Lymphoc & & $1.001(0.977-1.025)$ & NS \\
\hline Neutroph & & $1.010(0.989-1.031)$ & NS \\
\hline Eosinoph & & $0.994(0.929-1.064)$ & NS \\
\hline CRP & & $0.786(0.380-1.622)$ & NS \\
\hline Steroids wi & /without cytotoxic agents ${ }^{\#}$ & $1.045(0.682-1.602)$ & NS \\
\hline \multicolumn{4}{|c|}{ Multivariate Cox analysis } \\
\hline Smokers & & $0.585(0.342-1.001)$ & 0.050 \\
\hline FVC \% pre & & $0.979(0.964-0.995)$ & 0.011 \\
\hline
\end{tabular}

HR: hazard ratio; PFT: pulmonary function test; FVC: forced vital capacity; \% pred: \% predicted; $D L, C O$ : diffusing capacity of the lung for carbon monoxide; TLC: total lung capacity; BAL: bronchoalveolar lavage; CRP: C-reactive protein; NS: nonsignificant. ${ }^{\#}$ : within 30 days prior to RD; ${ }^{\top}$ : TLC $\%$ pred was excluded from the multivariate analysis due to the close correlation between FVC \% pred and TLC \% pred $(r=0.765 ; p<0.001)$.

suggest that AE tends to occur in patients with advanced disease (before death).

There was an increased risk of opportunistic infections in patients with IPF, which may be due to prior treatment with steroids with or without cytotoxic agents, although we could not demonstrate this effect clearly in this study (supplementary Table E3) [22-25]. Because the clinical features of infection are similar to AE, infection, particularly opportunistic infection, was the most important and difficult differential diagnosis of AE. In most reports, including the present study, infection was the second most common cause of RD or death. These findings may suggest a possibility that AE may be a masked or undiagnosed infection. Viral infection has also been suggested as a possible cause of AE [26, 27]. Interestingly, CRP levels were elevated in both conditions, although they were much higher in infections than in $\mathrm{AE}$, and CRP levels were a significant prognostic factor of AE (table 6). These findings may suggest that inflammation can be one pathogenic mechanism contributing to AE.

The outcome of AE in earlier reports was invariably very high $[13,16,28]$, probably due to the inclusion of only very severe cases. However, more recent studies reported better outcomes (9-month mortality rate $20 \%$ ) [29, 30]. In the present study, the in-hospital and 90-day mortalities were 50.0 and $60.0 \%$, respectively; however, the mortality of patients requiring mechanical ventilation was $90.0 \%$ (supplementary Table E5).
TABLE 5 Comparison of the clinical features of the patients with acute exacerbation (AE) and the bilateral infection at the time of rapid deterioration (RD)

\begin{tabular}{|c|c|c|c|}
\hline Characteristics & $A E$ & Infection & $p$-value \\
\hline Patients & 90 & 37 & \\
\hline Age yrs & $65.3 \pm 7.9$ & $66.1 \pm 7.6$ & NS \\
\hline Males & $69(76.7)$ & $30(81.1)$ & NS \\
\hline Disease duration months & $16.5 \pm 24.5$ & $29.5 \pm 34.7$ & 0.014 \\
\hline $\begin{array}{l}\text { Steroid with/without cytotoxic } \\
\text { agent use }\end{array}$ & $56(62.2)$ & $20(54.1)$ & NS \\
\hline Duration" months & $3.4 \pm 3.8$ & $4.5 \pm 5.2$ & NS \\
\hline Last dose $\mathrm{mg}$ & $18.8 \pm 13.2$ & $18.4 \pm 15.0$ & NS \\
\hline Duration of dyspnoea days & $11.2 \pm 12.5$ & $6.1 \pm 7.4$ & 0.030 \\
\hline \multicolumn{4}{|l|}{ Initial symptoms } \\
\hline Documented fever & $18(20.0)$ & $19(51.4)$ & 0.001 \\
\hline Sputum production & $63(70.0)$ & 31 (83.8) & NS \\
\hline CRP $\mathrm{mg} \cdot \mathrm{dL}^{-1}$ & $8.3 \pm 6.8$ & $14.7 \pm 9.8$ & $<0.001$ \\
\hline $\mathrm{Pa}, \mathrm{O}_{2} / \mathrm{Fl}_{1} \mathrm{O}_{2}$ & $253 \pm 83$ & $228 \pm 91$ & NS \\
\hline \multicolumn{4}{|l|}{ BAL } \\
\hline Total cells $\cdot \mathrm{mm}^{-3}$ & $292 \pm 168$ & $349 \pm 342$ & NS \\
\hline Lymphocytes \% & $19.7 \pm 19.6$ & $8.1 \pm 7.5$ & 0.041 \\
\hline Neutrophils \% & $22.9 \pm 19.9$ & $55.2 \pm 28.9$ & 0.001 \\
\hline
\end{tabular}

Data are presented as $n$, mean $\pm S D$ or $n(\%)$, unless otherwise stated. CRP: C-reactive protein; $\mathrm{Pa}_{1} \mathrm{O}_{2}$ : arterial oxygen tension; $\mathrm{Fl}, \mathrm{O}_{2}$ : inspiratory oxygen fraction; BAL: bronchoalveolar lavage; NS: nonsignificant. ${ }^{\#}$ : within 30 days prior to RD; ? steroid (prednisolone) treatment.

The univariate logistic analysis showed that the duration of dyspnoea, $\mathrm{Pa}, \mathrm{O}_{2} / \mathrm{FI}_{1} \mathrm{O}_{2}$ ratio, $\mathrm{CRP}$ level and percentage of lymphocytes in BAL fluid were prognostic factors; however, in the multivariate analysis, only the CRP level was an independent risk factor (table 6). Our study clearly showed that $\mathrm{AE}$ exerted a serious impact on the overall survival of patients (fig. $1 \mathrm{~b}$ and supplementary Table E7). The multivariate Cox analysis revealed that $\mathrm{AE}$ was a significant predictor of poor prognosis. Old age, low FVC, low DL,CO and steroids with or without cytotoxic agent treatments were also independent predictors.

Because this was a retrospective study, it has several limitations. 1) Although we tried to perform investigations according to the protocol, not all patients underwent a complete work-up. BAL and/or endotracheal aspiration were performed in $52.8 \%$ and echocardiography and/or brain natiuretic peptide (BNP) in $55.2 \%$, although all patients with any suspicion of cardiovascular problems underwent echocardiography and BNP with consultation to cardiology. Similarly, embolism computed tomography was performed in $21 \%$, although the clinical features (including HRCT findings) of nonperformers were inconsistent with pulmonary embolism without predisposition. Therefore, we believe the risk of misclassifying pulmonary embolism or heart failure was not high. The most difficult differential diagnosis was infection, as previously described. 2) Although we tried to obtain information from all of the patients by telephone interviews and tracking to other hospitals, 34 out of 461 patients were still 

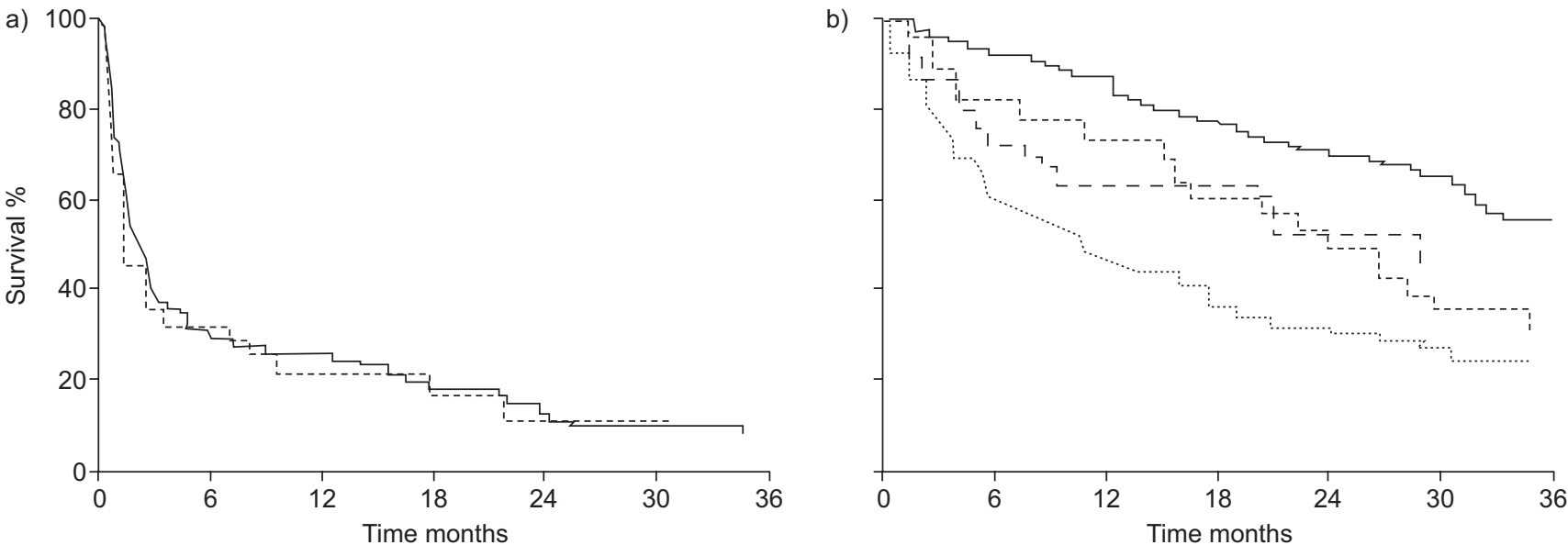

FIGURE 1. a) Comparison of survival curves (from rapid deterioration to death or last follow-up) between patients with acute exacerbation (AE) ( - ) and infection (---). b) Comparison of survival curves (from initial diagnosis to death or last follow-up) for patients with no rapid deterioration (RD) (-), AE (….), bilateral infection (----) and focal $\mathrm{RD}(---)$

unavailable during follow-up. 3) This study was the result of an analysis of a single tertiary referral center. However, the demographic features and average lung function of our subjects were comparable to other studies. 4) The median follow-up period was relatively short (22.9 months). However, considering the short survival of IPF, this follow-up period was long enough to reveal the incidence, risk factors, prognostic factors and occurrence of multiple episodes of RD. Despite these limitations, this was the largest study

\begin{tabular}{|c|c|c|}
\hline Parameters & OR $(95 \% \mathrm{Cl})$ & p-value \\
\hline \multicolumn{3}{|l|}{ Univariate logistic analysis } \\
\hline Age & $1.022(0.969-1.078)$ & NS \\
\hline Male sex & $1.455(0.543-3.895)$ & NS \\
\hline Disease duration & $0.994(0.977-1.011)$ & NS \\
\hline Steroid with/without cytotoxic agent use ${ }^{\#}$ & $0.828(0.353-1.943)$ & NS \\
\hline Duration & $1.142(0.932-1.399)$ & NS \\
\hline Last dose & $1.034(0.990-1.081)$ & NS \\
\hline Duration of dyspnoea & $0.939(0.902-0.978)$ & 0.003 \\
\hline Documented fever & $2.364(0.799-6.989)$ & NS \\
\hline Sputum production & $1.705(0.684-4.252)$ & NS \\
\hline $\mathrm{Pa}, \mathrm{O}_{2} / \mathrm{Fl}_{1} \mathrm{O}_{2}$ & $0.989(0.983-0.996)$ & 0.001 \\
\hline CRP & $1.087(1.009-1.172)$ & 0.029 \\
\hline \multicolumn{3}{|l|}{ BAL } \\
\hline Total cells & $0.998(0.992-1.003)$ & NS \\
\hline Lymphocytes & $0.905(0.826-0.992)$ & 0.033 \\
\hline Neutrophils & $1.055(0.996-1.118)$ & 0.070 \\
\hline \multicolumn{3}{|l|}{ Multivariate logistic analysis } \\
\hline CRP & $2.467(1.030-5.911)$ & 0.043 \\
\hline BAL lymphocytes & $0.869(0.737-1.024)$ & 0.093 \\
\hline
\end{tabular}

evaluating $\mathrm{AE}$ and $\mathrm{RD}$ and the first study using the criteria of COLLARD et al. [2] for AE. The criteria of COLLARD et al. [2] may overestimate the occurrence of $\mathrm{AE}$, because negative culture results cannot completely rule out the possibility of infection

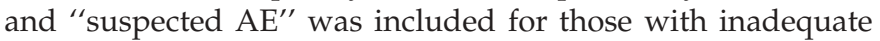
work-ups. However, when we reanalysed our data using only the cases with definite $\mathrm{AE}$ (data not shown), the results were similar.

In conclusion, we show that RD is relatively common during the course of IPF (one-third of IPF patients) and AE was the most frequent cause of RD, followed by infection. Low FVC and never having smoked were risk factors for $\mathrm{AE}$, and CRP at the time of AE was a prognostic factor. AE exerted a serious impact on the overall survival of patients with IPF, and old age, low FVC and DL,CO, and immunosuppressive treatments were other independent predictors of poor prognosis.

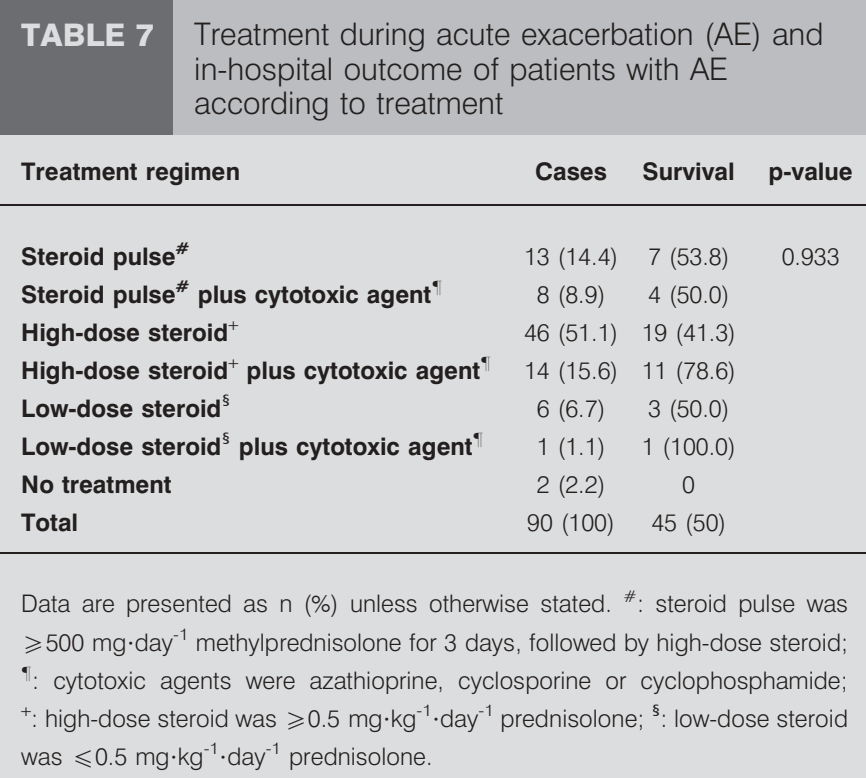




\begin{tabular}{|c|c|c|c|}
\hline \multirow{2}{*}{$\begin{array}{l}\text { TABLE } 8 \\
\text { Parameters }\end{array}$} & \multicolumn{3}{|c|}{$\begin{array}{l}\text { Prognostic factors for the overall survival from } \\
\text { the initial diagnosis of idiopathic pulmonary } \\
\text { fibrosis }\end{array}$} \\
\hline & & HR $(95 \% \mathrm{Cl})$ & p-value \\
\hline \multicolumn{4}{|c|}{ Univariate Cox analysis } \\
\hline Age & & $1.016(1.001-1.031)$ & 0.032 \\
\hline Male sex & & $0.910(0.685-1.209)$ & NS \\
\hline Smoking & & $0.737(0.568-0.956)$ & 0.021 \\
\hline \multicolumn{4}{|c|}{ PFT \% pred } \\
\hline FVC & & $0.976(0.968-0.984)$ & $<0.001$ \\
\hline$D\llcorner, C O$ & & $0.978(0.971-0.986)$ & $<0.001$ \\
\hline TLC & & $0.975(0.965-0.984)$ & $<0.001$ \\
\hline \multicolumn{4}{|l|}{ BAL } \\
\hline Macroph & & $1.003(0.993-1.014)$ & NS \\
\hline Lymphoc & & $0.998(0.985-1.012)$ & NS \\
\hline Neutroph & & $0.996(0.980-1.012)$ & NS \\
\hline Eosinoph & & $0.979(0.941-1.018)$ & NS \\
\hline CRP & & $1.073(0.808-1.423)$ & NS \\
\hline Steroid with & without cytotoxic agent & $1.529(1.177-1.986)$ & 0.001 \\
\hline Occurrence & $A E^{\#}$ & $2.770(2.132-3.599)$ & $<0.001$ \\
\hline \multicolumn{4}{|c|}{ Multivariate Cox analysis } \\
\hline Age & & $1.017(1.001-1.033)$ & 0.032 \\
\hline \multicolumn{4}{|l|}{ PFT \% pred } \\
\hline FVC & & $0.987(0.977-0.997)$ & 0.009 \\
\hline$D \mathrm{~L}, \mathrm{CO}$ & & $0.985(0.976-0.994)$ & 0.001 \\
\hline Steroid with & without cytotoxic agent & $1.552(1.113-2.164)$ & 0.010 \\
\hline Occurrence & of $A E$ & $2.592(1.888-3.560)$ & $<0.001$ \\
\hline
\end{tabular}

HR: hazard ratio; PFT: pulmonary function test; \% pred: \% predicted; FVC: forced vital capacity; $D \mathrm{~L}, \mathrm{CO}$ : carbon monoxide diffusing capacity of the lung; TLC: total lung capacity; BAL: bronchoalveolar lavage; CRP: C-reactive protein; AE: acute exacerbation; NS: not significant. ${ }^{\#}$ : overall occurrence during follow up; ${ }^{\bullet:}$ TLC $\%$ pred was excluded from the multivariate analysis due to the close correlation between FVC and TLC \% pred $(r=0.765 ; p<0.001)$

\section{STATEMENT OF INTEREST}

None declared.

\section{ACKNOWLEDGEMENTS}

The authors thank the excellent statistical support of S-C. Yun (University of Ulsan College of Medicine, Seoul, South Korea).

\section{REFERENCES}

1 Kim DS, Collard HR, King TE Jr. Classification and natural history of the idiopathic interstitial pneumonias. Proc Am Thorac Soc 2006; 3: 285-292.

2 Collard HR, Moore BB, Flaherty KR, et al. Acute exacerbations of idiopathic pulmonary fibrosis. Am J Respir Crit Care Med 2007; 176: 636-643.

3 Panos RJ, Mortenson RL, Niccoli SA, et al. Clinical deterioration in patients with idiopathic pulmonary fibrosis: Causes and assessment. Am J Med 1990; 88: 396-404.

4 American Thoracic Society/European Respiratory Society International Multidisciplinary Consensus Classification of the Idiopathic Interstitial Pneumonias. This Joint Statement of the American Thoracic Society (ATS), and the European Respiratory Society (ERS) was adopted by the ATS Board of Directors, June
2001 and by The ERS Executive Committee, June 2001. Am J Respir Crit Care Med 2002; 165: 277-304.

5 Jegal Y, Kim DS, Shim TS, et al. Physiology is a stronger predictor of survival than pathology in fibrotic interstitial pneumonia. Am J Respir Crit Care Med 2005; 171: 639-644.

6 Kim DS, Park JH, Park BK, et al. Acute exacerbation of idiopathic pulmonary fibrosis: frequency and clinical features. Eur Respir J 2006; 27: 143-150.

7 Park JH, Kim DS, Park IN, et al. Prognosis of fibrotic interstitial pneumonia: idiopathic versus collagen vascular disease-related subtypes. Am J Respir Crit Care Med 2007; 175: 705-711.

8 Wanger J, Clausen JL, Coates A, et al. Standardisation of the measurement of lung volumes. Eur Respir J 2005; 26: 511-522.

9 Miller MR, Hankinson J, Brusasco V, et al. Standardisation of spirometry. Eur Respir J 2005; 26: 319-338.

10 MacIntyre N, Crapo RO, Viegi G, et al. Standardisation of the single-breath determination of carbon monoxide uptake in the lung. Eur Respir J 2005; 26: 720-735.

11 Jeon K, Chung MP, Lee KS, et al. Prognostic factors and causes of death in Korean patients with idiopathic pulmonary fibrosis. Respir Med 2006; 100: 451-457.

12 Nagai S, Kitaichi M, Hamada K, et al. Hospital-based historical cohort study of 234 histologically proven Japanese patients with IPF. Sarcoidosis Vasc Diffuse Lung Dis 1999; 16: 209-214.

13 Stern J-B, Mal H, Groussard O, et al. Prognosis of patients with advanced idiopathic pulmonary fibrosis requiring mechanical ventilation for acute respiratory failure. Chest 2001; 120 : 213-219.

14 Saydain G, Islam A, Afessa B, et al. Outcome of patients with idiopathic pulmonary fibrosis admitted to the intensive care unit. Am J Respir Crit Care Med 2002; 166: 839-842.

15 Fernandez-Perez ER, Yilmaz M, Jenad H, et al. Ventilator settings and outcome of respiratory failure in chronic interstitial lung disease. Chest 2008; 133: 1113-1119.

16 Blivet S, Philit F, Sab JM, et al. Outcome of patients with idiopathic pulmonary fibrosis admitted to the ICU for respiratory failure. Chest 2001; 120: 209-212.

17 Hwang WS. The rarity of pulmonary thromboembolism in asians. Singapore Med J 1968; 9: 276-279.

18 Khor GL. Cardiovascular epidemiology in the Asia-Pacific region. Asia Pac J Clin Nutr 2001; 10: 76-80.

19 Klatsky AL, Armstrong MA, Poggi J. Risk of pulmonary embolism and/or deep venous thrombosis in Asian-Americans. Am J Cardiol 2000; 85: 1334-1337.

20 Stein PD, Kayali F, Olson RE, et al. Pulmonary thromboembolism in Asians/Pacific Islanders in the United States: analysis of data from the National Hospital Discharge Survey and the United States Bureau of the Census. Am J Med 2004; 116: 435-442.

21 Kubo H, Nakayama K, Yanai M, et al. Anticoagulant therapy for idiopathic pulmonary fibrosis. Chest 2005; 128: 1475-1482.

22 Maeno Y, Sando Y, Ubukata M, et al. Pulmonary nocardiosis during immunosuppressive therapy for idiopathic pulmonary fibrosis. Respirology 2000; 5: 393-395.

23 Sugino K, Homma S, Takaya H, et al. [Fatal invasive pulmonary aspergillosis triggered by influenza $\mathrm{B}$ virus infection in an individual with idiopathic pulmonary fibrosis.] Nihon Kokyuki Gakkai Zasshi 2006; 44: 207-214.

24 Shachor Y, Schindler D, Siegal A, et al. Increased incidence of pulmonary tuberculosis in chronic interstitial lung disease. Thorax 1989; 44: 151-153.

25 Chung MJ, Goo JM, Im J-G. Pulmonary tuberculosis in patients with idiopathic pulmonary fibrosis. Eur J Radiol 2004; 52: $175-179$.

26 Tang Y-W, Johnson JE, Browning PJ, et al. Herpesvirus DNA is consistently detected in lungs of patients with idiopathic pulmonary fibrosis. J Clin Microbiol 2003; 41: 2633-2640. 
27 Tsukamoto K, Hayakawa H, Sato A, et al. Involvement of EpsteinBarr virus latent membrane protein 1 in disease progression in patients with idiopathic pulmonary fibrosis. Thorax 2000; 55: 958-961.

28 Ambrosini V, Cancellieri A, Chilosi M, et al. Acute exacerbation of idiopathic pulmonary fibrosis: report of a series. Eur Respir J 2003; 22: 821-826.
29 Azuma A, Nukiwa T, Tsuboi E, et al. Double-blind, placebocontrolled trial of pirfenidone in patients with idiopathic pulmonary fibrosis. Am J Respir Crit Care Med 2005; 171: 1040-1047.

30 Churg A, Muller NL, Silva CI, et al. Acute exacerbation (acute lung injury of unknown cause) in UIP and other forms of fibrotic interstitial pneumonias. Am J Surg Pathol 2007; 31: 277-284. 